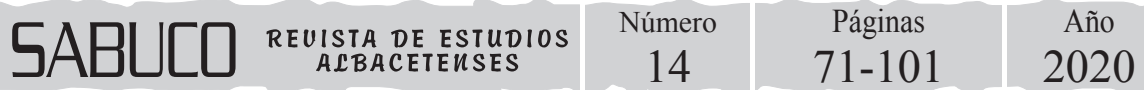

\section{MIERA Y MERERAS DE ENEBRO (JUNIPERUS OXYCEDRUS L.) EN ALBACETE}

\section{CADE OIL AND CADE OIL OVENS OF PRICKLY JUNIPER (JUNIPERUS OXYCEDRUS L.) IN ALBACETE PROVINCE (SPAIN)}

\author{
Por \\ José FAJARDO RODRÍGUEZ ${ }^{(1)^{*}}$ \\ Tomás MORCILLO CUENCA ${ }^{(2)}$
}

Recibido: 20 de octubre de 2020

Aprobado: 30 de diciembre de 2020

(1). Universidad Popular de Albacete. Instituto de Estudios Albacetenses.

(2). Investigador independiente.

*correo de contacto: josefajard@gmail.com

Cómo citar este artículo:

Fajardo J. y Morcillo, T. (2020). Miera y mereras de enebro (Juniperus oxycedrus L.) en Albacete. Sabuco, 14: 71-101

http://doi.org/10.37927/sabuco.14_4 



\section{RESUMEN}

Se presenta en este artículo un estudio sobre el uso tradicional de la miera y las antiguas mereras en la provincia de Albacete. La miera es el alquitrán vegetal que se obtiene por destilación seca de las cepas de los enebros (Juniperus oxycedrus L.), empleado especialmente como desinfectante por parte de pastores y ganaderos. Este proceso tiene lugar en unos hornos específicos denominados localmente mereras, miereras u hornos de miera. Estos elementos aparecen en diversas fuentes documentales, se mantienen en la toponimia e incluso se conservan algunas de ellas, en diferentes estados de conservación, dispersas por la provincia de Albacete.

Palabras clave: Juniperus oxycedrus, miera, alquitrán de enebro, ganadería tradicional, Albacete (España).

\section{ABSTRACT}

This article presents a study on the traditional use of the cade oil (miera in Spanish) and the cade oil ovens in the province of Albacete (Spain). Cade oil is the vegetable tar that is obtained by dry distillation of prickly juniper wood (Juniperus oxycedrus L.), used especially as a disinfectant by shepherds and ranchers. This process take place in specific ovens called mereras, miereras or miera ovens. These elements appear in various documentary sources, they are kept in the toponymy and even there are some ovens scattered in Albacete province, in different states of conservation.

Key words: Juniperus oxycedrus, cade oil, traditional livestock, Albacete (Spain).

\section{INTRODUCCIÓN}

Conocemos como enebros en Albacete, las especies del género Juniperus (Cupressaceae) con hojas aciculares, comúnmente diferenciados en nuestra provincia de las sabinas, pertenecientes al mismo género aunque 
con hojas escuamiformes. Esta diferenciación es relativa y local, ya que en otras regiones españolas se aplica el nombre de enebros a especies de hojas escuamiformes. En el caso de las sabinas, presentan también hojas aciculares aunque sólo en sus primeros años de vida, siendo sustituidas pronto por las hojas adultas, en forma de escama.

Las especies del género Juniperus son plantas longevas y de crecimiento lento, con maderas aromáticas.

En cuanto a sabinas, encontramos tres especies en nuestra provincia. La sabina albar (Juniperus thurifera L.) forma en Albacete grandes masas forestales, donde es dominante (sabinares) o mixta con otras especies, básicamente encinas o quejigos, en ambientes continentales. Los mejores sabinares se localizan en el Campo de Montiel y en Nerpio. La sabina negral (Juniperus phoenicea L.) con una ecología más amplia que la anterior, aparece dispersa en matorrales y bosques mediterráneos por toda la provincia. Finalmente, la sabina rastrera (Juniperus sabina L.), es muy escasa en la provincia, estando restringida a unas pocas localidades en torno al Calar del Mundo (Charco et al., 2008).

Existen en la provincia de Albacete dos taxones de Juniperus con hojas aciculares (enebros):

Juniperus communis subsp. hemisphaerica (C. Presl) Nyman. Conocido en Albacete como enebra, nebra o enebriza. Arbusto dioico con hojas aciculares con una única banda blanca en el haz y gálbulos (enebrinas) negro azulados (Figura 1). Se restringe a las zonas más altas y frescas de las sierras de Alcaraz y Segura. Aunque escasa y localizada en esta provincia, es una especie ampliamente distribuida por el centro y norte de Europa que alcanza el Mediterráneo en las montañas. Estas enebrinas son las que se emplean para aromatizar la ginebra.

Juniperus oxycedrus L. Llamado en Albacete enebro, en ocasiones nebro. Se dan dos subespecies en nuestra provincia: la subespecie oxycedrus, extendida por toda la provincia y la subespecie badia, mucho más limitada, con algunas localidades en el suroeste y sur de la provincia (Charco et al., 2008). Es un arbusto dioico o arbolillo (especialmente en el caso de la subespecie badia), con hojas aciculares con dos bandas blancas en el haz y gálbulos (conos femeninos) de color pardo rojizo (Figura 2). Pies masculinos y femeninos tienen distinto porte; abierto, con ramas 


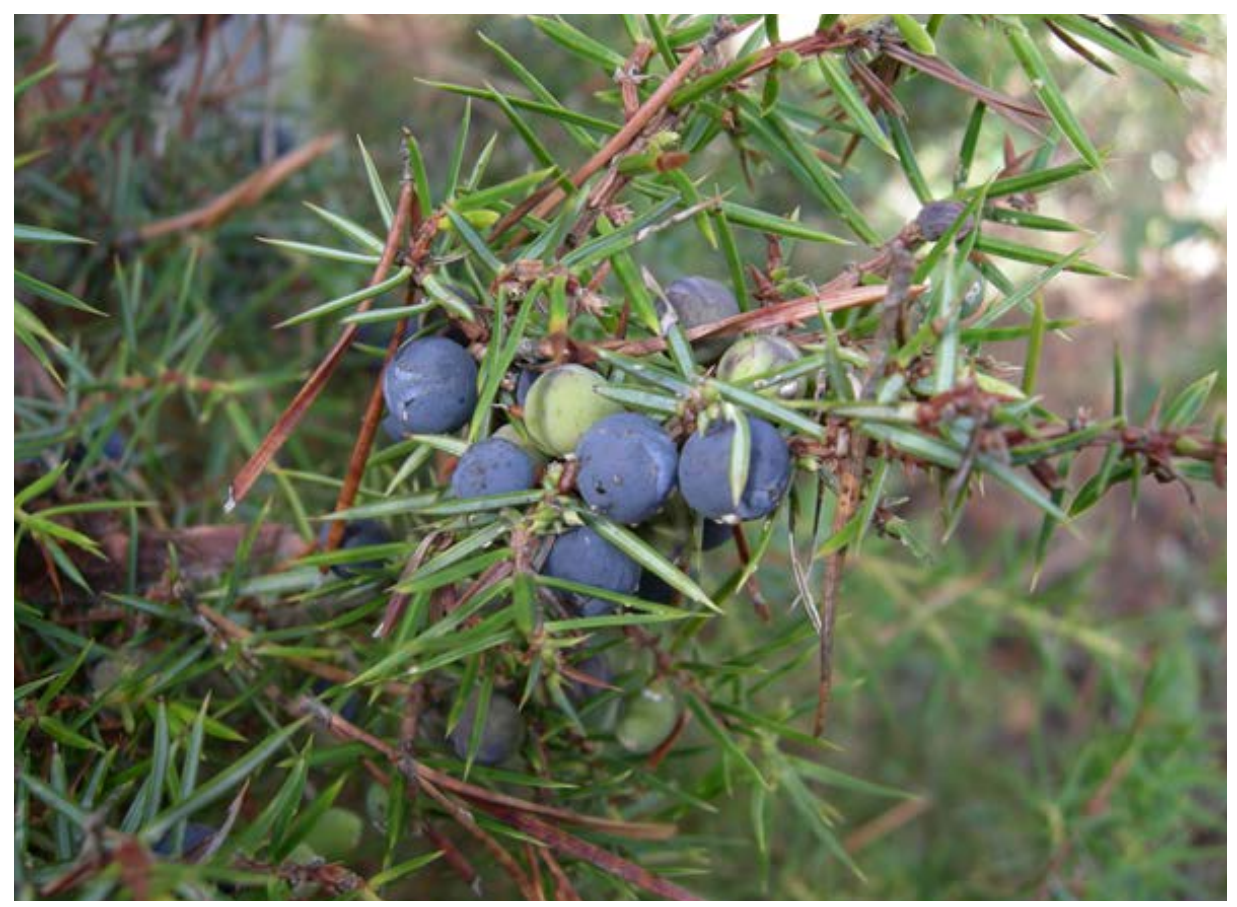

Figura 1. Juniperus communis subsp. hemisphaerica. Pie femenino con gálbulos (Foto: José Fajardo).

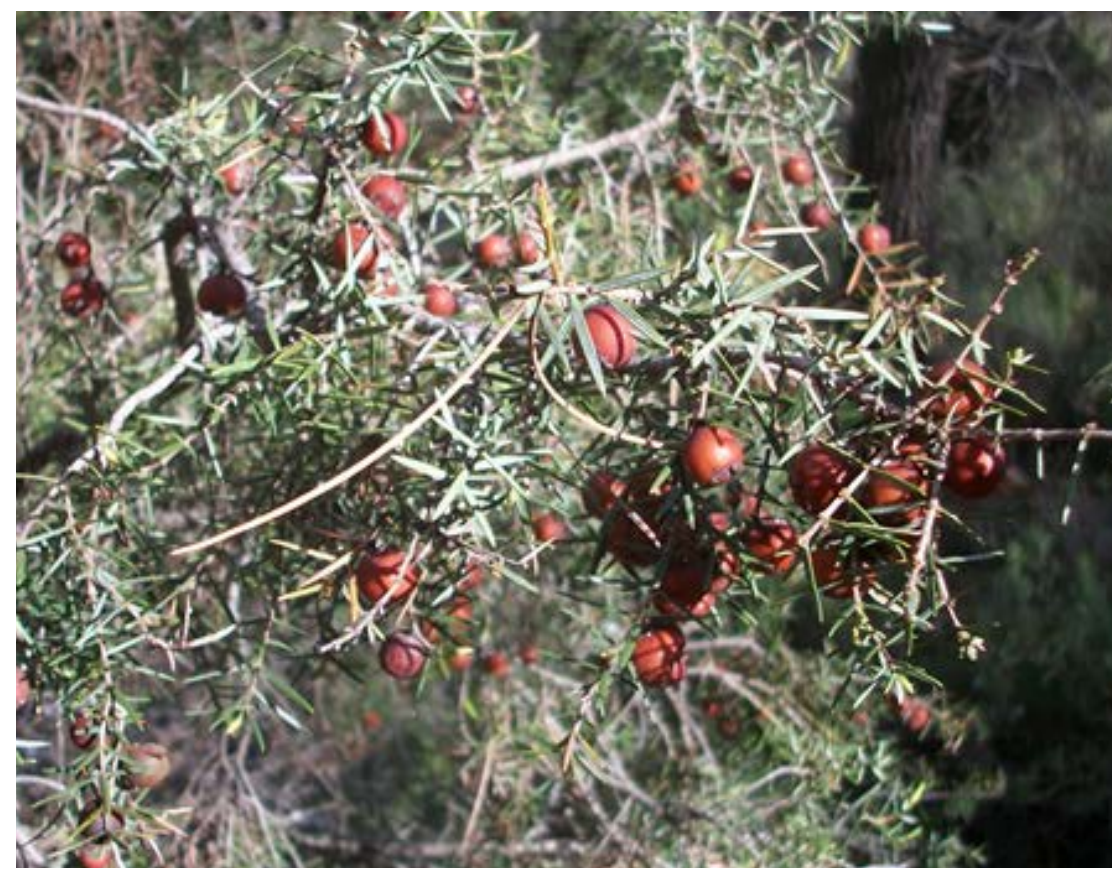

Figura 2. Juniperus oxycedrus. Pie femenino con gálbulos (Foto: José Fajardo). 
algo péndulas en los pies femeninos y erguido y más compacto en el caso de los pies masculinos. Es una especie mediterránea (Figura 3), que se distribuye por toda la provincia, donde es muy común, formando pequeños enebrales o en matorrales mediterráneos mixtos, acompañando a menudo a la coscoja o maraña (Quercus coccifera L.). Más raras son las dehesas con pies arbóreos de enebros (en este caso de la subespecie badia) como se pueden ver en la Sierra del Relumbrar (Villapalacios).

Existen en la provincia de Albacete algunos enebros singulares por su porte y tamaño como el de la Casa Olivares (Montalvos), el de la Dehesa Clementina (Alatoz), el de los Chorretites de Arriba (Nerpio), el de los Habares en Pedro Andrés (Nerpio) y el del Cortijo del Duende en Reolid (Salobre) (Benlloch y Martín, 2015).

Este enebro es el usado para obtener la miera, término procedente del latín pix mera, pez pura (DRAE).

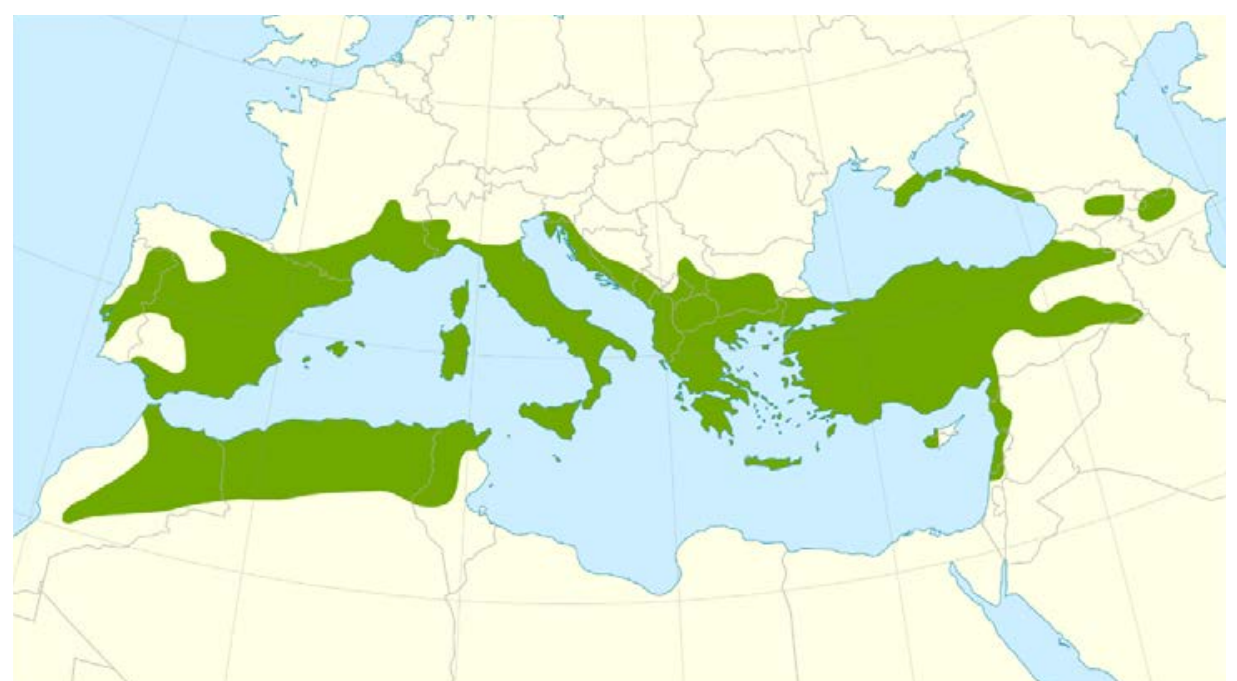

Figura 3. Área de distribución mundial de Juniperus oxycedrus (Vilar et al, 2016)

\section{Objetivos}

- Dar a conocer la miera como un uso tradicional del enebro y su importancia y aprovechamientos como recurso natural en la provincia de Albacete.

- Revisar la documentación histórica referida a la miera y las mereras en la provincia de Albacete. 
- Localizar las mereras de la provincia de Albacete, según la toponimia, las referencias documentales y los testimonios de informantes y colaboradores.

- Catalogar y recuperar los hornos de miera aún visibles.

\section{MATERIAL Y MÉTODOS}

El artículo muestra por una parte datos obtenidos a partir del trabajo de campo etnográfico con pastores de la provincia de Albacete, a través de entrevistas abiertas y semiestructuradas sobre el pastoreo tradicional y por otra parte, una revisión de fuentes documentales del Archivo Histórico Provincial de Albacete, Biblioteca Digital del Instituto de Estudios Albacetenses y diversas referencias bibliográficas sobre la miera.

Ha habido que filtrar cuidadosamente las referencias documentales donde aparece la palabra miera, ya que con esta misma denominación aparece también la resina de pino en bruto en diversos documentos y referencias relacionados con la regulación antigua de los aprovechamientos forestales.

Las entrevistas se han ido registrando por escrito en nuestros cuadernos de campo y algunas de ellas en grabaciones de voz. Hemos obtenido material gráfico tanto de las entrevistas como de las mereras visitadas en el campo.

Se ha revisado la presencia de las mereras (también registradas como miereras) en la toponimia de la provincia de Albacete, a través del rastreo de los mapas topográficos del Instituto Geográfico Nacional y de su visor en línea IBERPIX-4.

\section{RESULTADOS}

\subsection{Usos tradicionales del enebro en Albacete}

El enebro (Juniperus oxycedrus L.) es un arbusto muy común en los matorrales y bosques mediterráneos de la provincia de Albacete. Los múltiples usos tradicionales de esta especie en la provincia han sido recogidos en diversos trabajos etnobotánicos (Sánchez et al., 1994, Verde et al., 1998a, Verde et al., 1998b, Fajardo et al., 2000, Verde et al., 2008). 
La madera de enebro, dura y aromática se emplea para hacer badajos de cencerros y ocasionalmente para garrotes y pipas de fumar. Los gálbulos del enebro (conos femeninos carnosos), llamados "bolos", se utilizan como condimento para platos de caza y se usan en medicina popular como diuréticos.

Con el agua en que se había cocido su raíz se hacían enjuagues para calmar el dolor de muelas. Los gálbulos se tomaban directamente en casos de dolores, molestias de estómago y reúma, siempre un número impar, tres, cinco, siete o nueve. El cocimiento se toma también para tratar la diabetes y como diurético.

Existía también la creencia de que los enebros podían quitar las verrugas, para ello, se apalea una mata de enebro al tiempo que se le dice: buenos días, enebro, enebroso, aquí está (fulano) el verrugoso.

En veterinaria popular, además de la miera, de la que hablaremos más adelante, las ramas de enebro, cortando una púa afilada (llamada astabón o pita), se usaban para curar las nubes de los ojos de las ovejas, pinchadas en la oreja y también para las picaduras de las víboras, pinchando con ellas la inflamación producida por la picadura. Los bolos (gálbulos) y tallos se cocían para lavar las heridas de las ovejas y las que tenían roña.

En Alatoz y Carcelén, las cepas de enebro se echaban a los aljibes para desinfectar el agua, especialmente después de que hubiera entrado en un aljibe agua de piedra (el agua de una tormenta con granizo). Se pensaba que si los animales bebían de esta agua se producían abortos (Pepe Gómez, com. pers.).

En Casas de Lázaro se dice: de padres cepas, hijos enebros (Virgilio Picazo, com. pers.).

\subsection{La miera}

Las cepas de los enebros, llamadas también porras, están formadas por una madera roja, muy aromática, con un veteado intenso de color rojizo (Figura 4). De los usos tradicionales del enebro, el más importante ha sido la obtención de la miera, este es el alquitrán vegetal o brea que se obtiene por la destilación de la madera de su cepa. El uso de la miera estaba extendido en toda la provincia y su producción dispersa por las zonas 
de enebrales y matorrales mediterráneos. Hoy en día, sólo la conocen y la han usado los pastores de más edad.

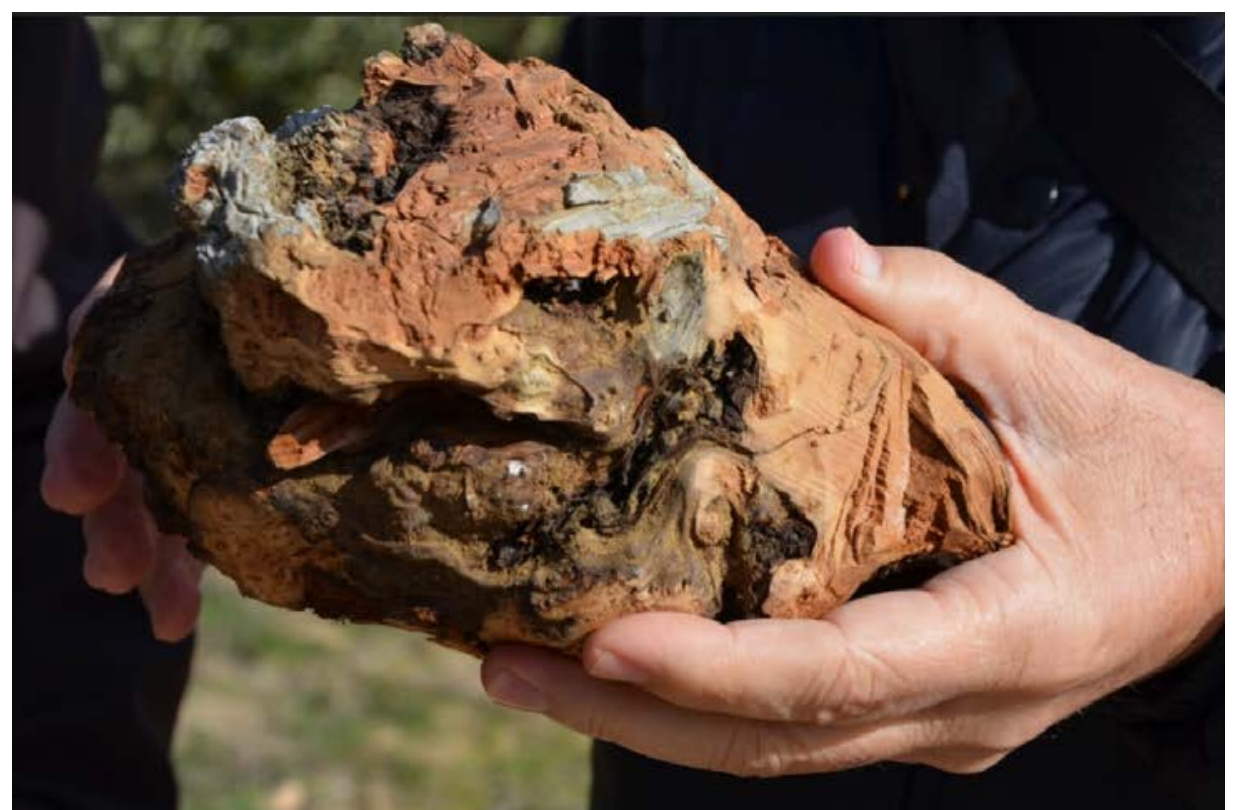

Figura 4. Cepa de enebro, materia prima para la elaboración de la miera (Foto: José María López).

En la provincia de Albacete destacan dos localidades que han sido tradicionalmente referencia en la producción de miera: una es Ossa de Montiel, donde aún se sigue elaborando miera, y la otra es Alatoz, como recoge un dicho popular, muy conocido en su entorno y con diversas variantes (Cruz Herrera, 2004):

En Casas de Ves, rabotes, gente noble en Alborea; en Alcalá, rabilancos, criados entre las piedras; en Fuentealbilla, raneros, y cojos en Villamalea; en Carcelén, gordos nabos, en Alatoz, mucha miera; y en Abengibre, mucha agua, pero son muchas las puercas.

Pastores en Higueruela, que son hijos de pastoras, que también son madres buenas. En Carcelén, gordos nabos, que lo requiere la tierra; Alatoz, la mucha miera, y en las Casas de Juan Núñez, muchos carros y galeras.

En Carcelén, gordos nabos, en Alatoz mucha miera, para untarles el rabo a los que vienen de fuera. 
A los de Alatoz, en la comarca, se les conoce también como los de la miera (Cruz Herrera, 2004).

De Segundo Mínguez, de Casas de Juan Gil (Carcelén), hemos recogido una versión más extendida que muestra también la relación de estos pueblos albaceteños con las localidades cercanas de la provincia de Valencia.

En Carcelén, gordos nabos/En Alatoz mucha miera

En las Casas de Juan Núñez muchos carros y galeras

En el Pozo los centenos/Pastores en Higueruela

En las Hoyas de Gonzalo produce mucho la avena

En Teresa cabezones/En Jarafuel colmeneros

En Jalance pelarranas/En Cofrentes madereros

Hay que destacar por su valor documental el artículo divulgativo referido al aceite de enebro, sinónimo de la miera, elaborado por Eugenio Monesma (2017) y publicado en la página web de la productora Pyrene, especializada en documentales etnográficos. Además de dedicar varios videos a los hornos de miera y a la elaboración del aceite de enebro, en este artículo hace un recorrido por los usos de la miera y la importancia que tuvo este producto en la localidad tarraconense de Riba-Roja d'Ebre donde se conservan más de veinte hornos industriales para la elaboración de miera. También se muestran las huellas de las pequeñas mereras domésticas talladas en losas de roca en diversas localidades de Teruel, emparentadas con las que hemos encontrado en Alatoz. Menciona la evidencia de destilación de miera en Zaragoza, Teruel, Lérida y Castellón y describe el proceso de elaboración tradicional de este producto. Se cita también la gran importancia que alcanzó la elaboración de miera en el departamento francés de Var, en la Provenza. En cualquier caso, recomendamos la lectura de este documento para tener una visión más amplia de este tema (www.pyrenepv.com/aceite-enebro/).

La elaboración de la miera consiste en un proceso de destilación seca. Gracias a Gabriel Muñoz, de Ossa de Montiel, productor de plantas 
aromáticas, aceites esenciales y miera, hemos podido conocer el proceso de elaboración de este producto y los lugares antiguos donde se elaboraba, diversos parajes con abundancia de enebros. El horno interior se rellena desde arriba con trozos de cepas de enebro. Una vez cargado se cierra herméticamente la apertura superior. Envolviendo este horno (de ladrillo en las mereras más antiguas y de hierro en las más modernas) existe una cámara que se carga de leña y enciende (Figura 5).

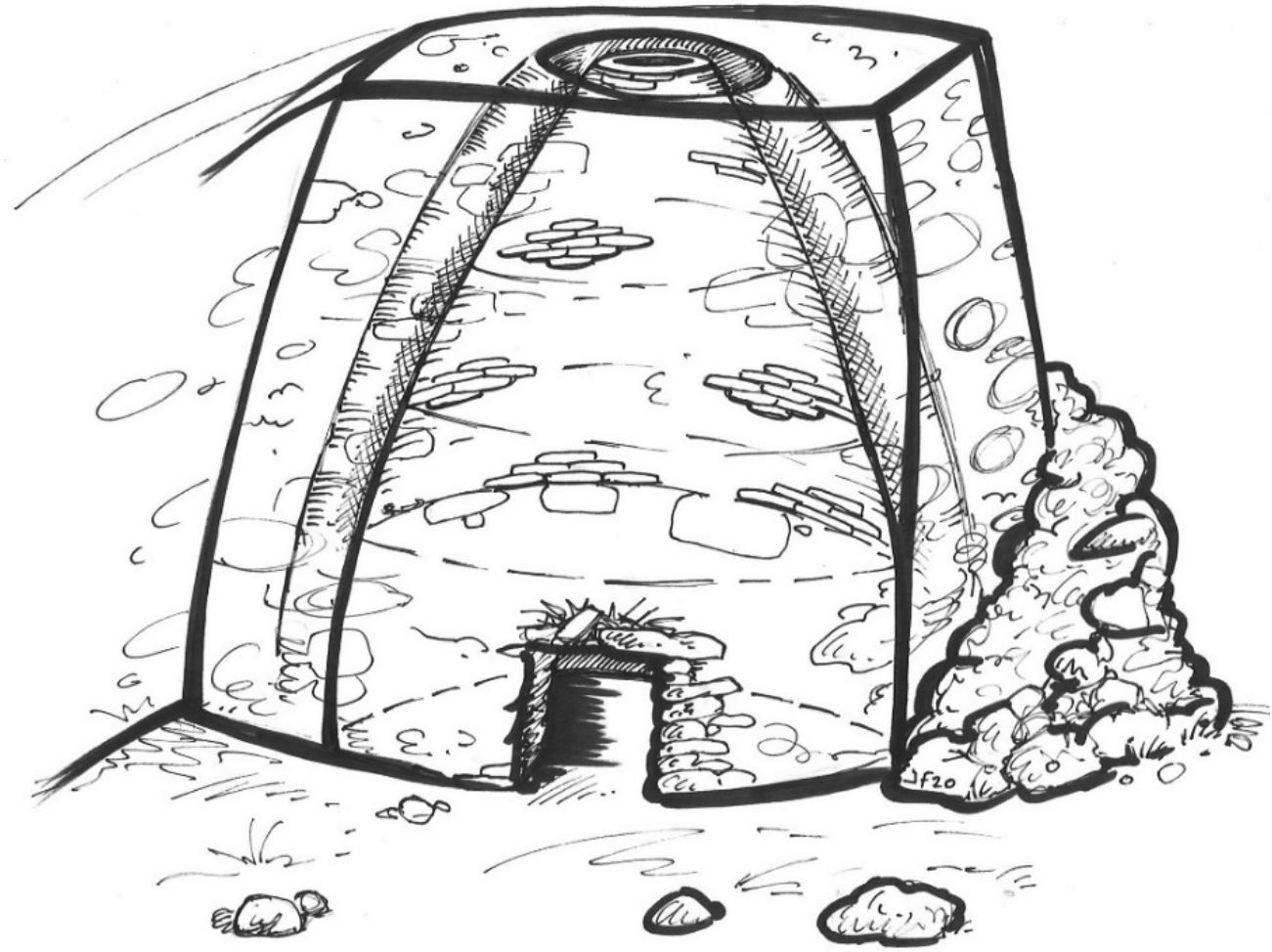

Figura 5. Esquema de una merera antigua, de piedra, conservada en Ossa de Montiel. Consta de un horno interno de unos $150 \mathrm{~cm}$. de diámetro y $3 \mathrm{~m}$. de altura, con la base de mampostería (en el dibujo la pieza central). En la base presenta una boca de descarga. A unos $120 \mathrm{~cm}$. de su base se comienza a cerrar por aproximación de hiladas con ladrillos dispuestos a cuchillo hasta la boca de carga. Entre este horno y el muro de piedra que lo recubre hay una cámara de combustión de unos $50 \mathrm{~cm}$. de anchura abierta en la parte superior de la merera. Aunque la planta del horno interior es circular, la estructura de mampostería que recubre el horno es de planta cuadrada de unos $4 \mathrm{~m}$. de lado. En una esquina de la merera está la rampa de carga por donde se subía tanto la madera de enebro como la leña para la destilación (Dibujo: José Fajardo). 
El humo sale por la abertura superior de la merera. Tras un tiempo variable, el calor exterior produce la destilación de la miera que comienza a salir por un drenaje en la base de la merera donde se coloca un tubo que va a parar a una pileta de obra donde se produciría la decantación de la miera. Inicialmente sale una miera de poca calidad, que contiene la parte acuosa retenida en la madera y tras este destilado inicial, comienza a salir la miera pura, que se separa fácilmente (una vez fría) de la parte acuosa por su diferente densidad (la miera pura flota sobre la parte acuosa). Este es un aceite espeso, de color negruzco y olor muy intenso, con fuertes matices de humo. El proceso termina cuando cesa la exudación de miera.

El acceso a la parte superior de las mereras es una rampa para poder cargarlas tanto de cepas de enebro como de leña para la combustión. Como los hornos que contienen las porras de los enebros se cargan por arriba, una vez cargados hay que cerrarlos por la parte superior, tanto en las mereras de piedra como en las de hierro.

En alguna de las mereras que hemos podido estudiar, como en El Bonillo, se ven muchas tobas en las paredes derruidas. Al menos, estas piedras porosas han formado parte del muro exterior, lo que no hemos podido comprobar es si el horno interior (desaparecido en este caso) estaba elaborado con este material, muy empleado antiguamente en la construcción de los hornos de pan.

En Alatoz, en el Cerro de las Mereras, al menos en dos restos que hemos encontrado (gracias a Pepe Gómez) no existen esas grandes construcciones de piedra. En un caso, se aprecia en una ladera la base de lo que sería un horno y en otro, encontramos en una cingla rocosa una pequeña depresión de la que parte un canal de drenaje que serviría para recoger la miera destilada (Figura 6).

La madera de enebro, una vez destilada, quedaba carbonizada y se comercializaba para su uso como carbón vegetal. En El Bonillo se dice sobre este tipo de leña: eres más malo que un ceporro de enebro, que ni calienta ni arde y sólo echa humo (Ramón F. Chillerón).

Gabriel Muñoz ha elaborado también miera con madera de sabina (Juniperus thurifera), aunque la calidad de este producto es inferior a la elaborada con enebro. 

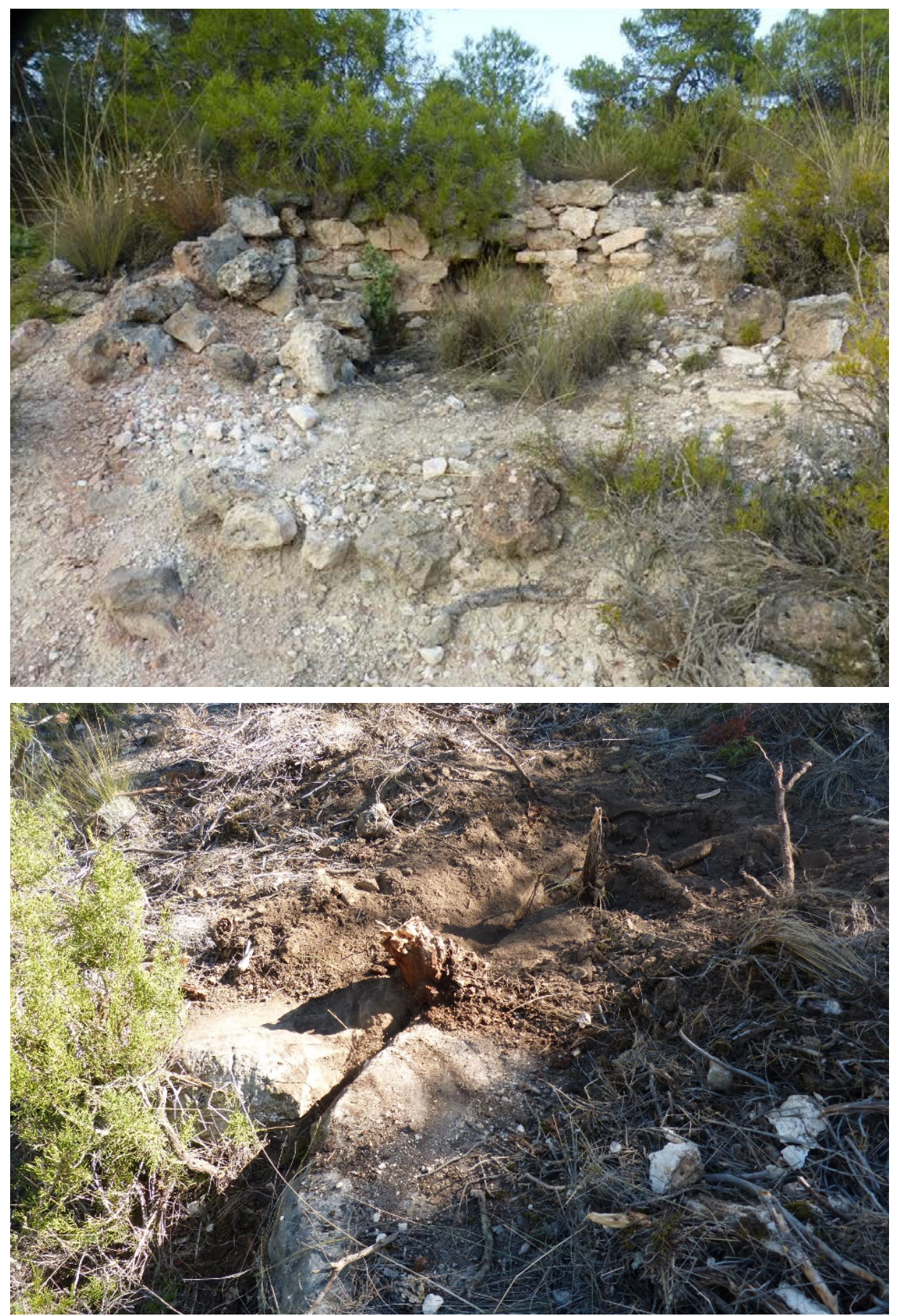

Figura 6. Cerro de las Mereras (Alatoz). Arriba, restos de una merera de mampostería en un talud. Abajo, restos del drenaje de una merera tallado en una losa de roca. (Foto: José Fajardo). 
En la actualidad, en la provincia de Albacete se sigue elaborando miera únicamente en Ossa de Montiel (Figura 7).

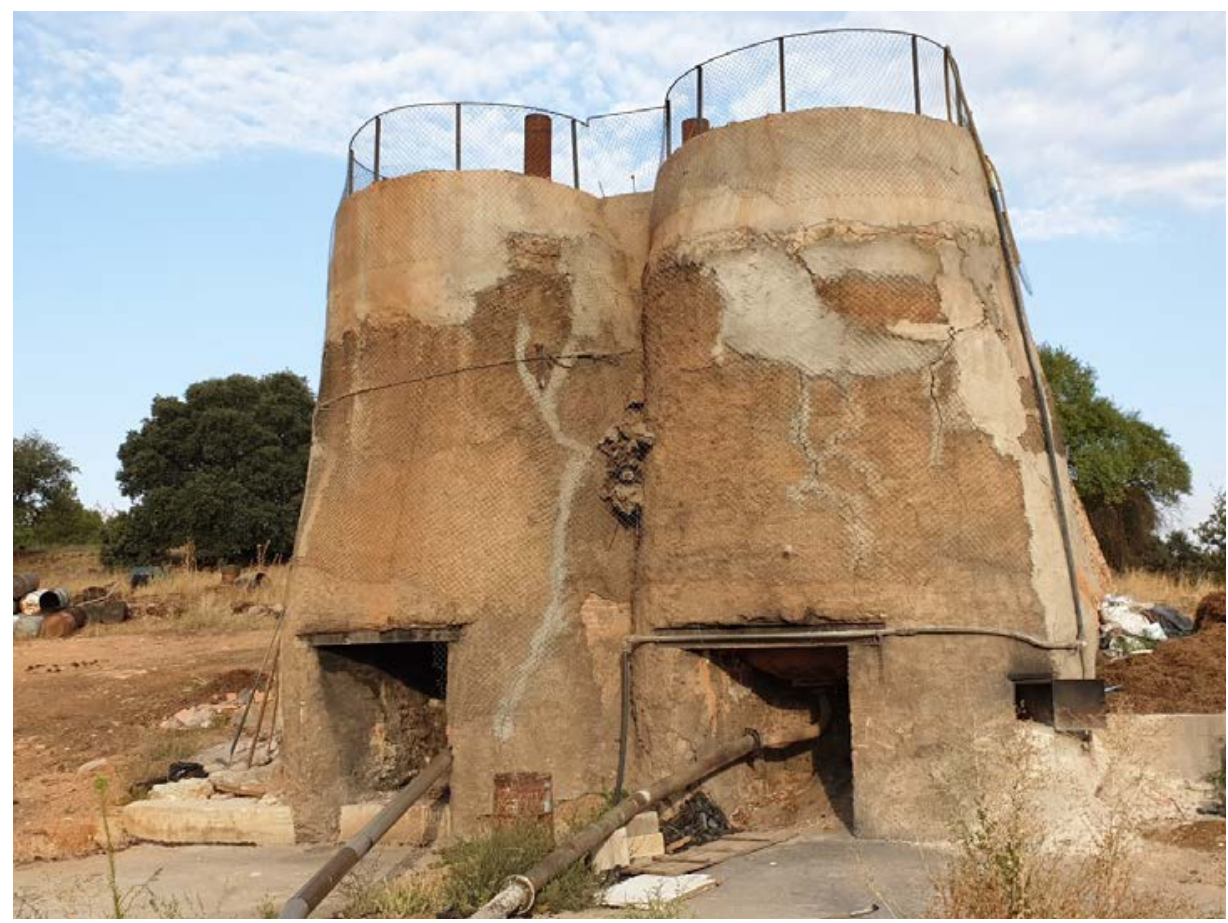

Figura 7. Mereras en uso de la empresa familiar Peñarrubia del Alto Guadiana en Ossa de Montiel. (Foto: Kica Muñoz).

\subsection{Usos de la miera}

Se usa o se ha usado en toda el área de distribución mundial del enebro. En la composición de la miera abundan los polifenoles y otras sustancias de gran poder desinfectante. El principal componente es el cadineno, un sesquiterpeno. Contiene entre un 17 y un $26 \%$ de fenoles (especialmente guayacol y cresol), carburos y un alcohol, el cardinol (VV. AA., 2005).

Se ha evaluado in vitro la actividad antimicrobiana de la miera con resultados positivos en diversas cepas de microorganismos (Abdellah et al., 2018).

Por su concentración en fenoles, es una sustancia peligrosa si no se usa adecuadamente. Ya cuentan los pastores que cuando se echaban 
un poquito de miera impregnada en un trapito sobre una muela cariada, la muela se deshacía. Se han descrito varios casos de intoxicaciones en la literatura médica por la ingestión de miera y por su uso externo. En Turquía, un hombre que tomó una cucharada de miera, elaborada de forma casera, se intoxicó mostrando fiebre, hipotensión severa, fallo renal, hepatotoxicidad y quemaduras cutáneas severas en la cara. Tras once días de tratamiento se recuperó totalmente (Koruk et al, 2005).

En Marruecos, la miera es ampliamente usada en medicina popular, para enfermedades de la piel, pérdida de pelo, como antiparasitico, antiséptico, para la elaboración de productos cosméticos (jabones, cremas, champús). Oralmente, se administran unas pocas gotas para los gusanos intestinales. Se pone también una gota de miera en la nariz como profilaxis y también en la base de las jarras donde se pone agua para beber. En este mismo país, se dio un caso de intoxicación por uso externo de miera en un niño de un año, al que la madre aplicó abundante miera en las muñecas, en la frente y en la cara. Una hora después, el niño estaba inconsciente, con convulsiones y otros desórdenes que se descubrió que se debían a una insuficiencia renal que se pudo corregir con el tratamiento adecuado (Ezzaki et al, 2020). En la medicina popular marroquí, se emplea también para la tiña, untando con miera las zonas afectadas, después de afeitarlas (Cabezón, 1997).

En Oriente Medio, se emplea para tratar eczemas crónicos y psoriasis y otras enfermedades de la piel. Además, se emplea como parasiticida. Muy a menudo se emplea diluido en algún aceite o como parte de la composición de ungüentos y jabones (Al-Snafi, 2018). En el norte de África se usa en el tratamiento de enfermedades de la piel en animales, para curar heridas y como repelente de insectos para evitar que se desarrollen en heridas abiertas. En la actualidad se usa también en perfumes masculinos, donde se usa la miera rectificada dando notas a piel, humo, etc., como desinfectante en la composición de jabones y como aditivo alimentario, para carnes y pescados, aportando sabor a ahumado (VV.AA., 2005). En Turquía se usa como antirreumático, antiparásitos, antiséptico, eczemas, inflamaciones, heridas y cortes (Rivera et al, 2011).

En España, se ha utilizado ampliamente la miera con usos similares. En la Serranía de Cuenca se ponían unas gotas de miera en las muelas 
cariadas, también para calmar el dolor de oídos y como desinfectante de heridas, tanto en personas como en animales (Verde et al, 2008). En las comarcas del Alto Tajo y el Señorío de Molina (Guadalajara), la miera, llamada también en la zona aceite de enebro, se empleaba como medicinal para desinfectar heridas y hacer salir el pelo y en veterinaria popular para la sarna de las cabras y la roña de las ovejas (Blanco, Gutiérrez y Pintor, 2018).

En las sierras del suroeste de Albacete, la miera se usaba en medicina popular y veterinaria. En las personas, se empleaba para dolores de muelas, llagas de los pies, reumatismos, artrosis, catarros y lombrices. Para los animales, se usaba para curar escoceduras, desinfectar cascos de caballos y pezuñas, eliminar parásitos, etc. Se asperjaba con miera las entradas de casas y corrales para ahuyentar a las serpientes (Jordán Montes, 2018).

Según los datos de nuestras entrevistas, en la provincia de Albacete, la miera era uno de los equipamientos usuales en el hato de los pastores. La solían llevar en una botella pequeña, un trozo de cuerno de vaca llamado colodra o una botijuela de barro. Se usaba para:

- Como desinfectante dermatológico para animales, aplicándola sobre la piel en heridas, zonas afectadas de larvas de moscarda, sarna o roña.

- Para los abrevaderos, estaba generalizado el uso de la miera como desinfectante del agua en los tornajos donde bebían las reses, añadiendo unas gotas, decían también que así los animales toman mejor el agua. Se echaban unas gotas y se extendían sobre el agua con una pluma ya que flota y forma irisaciones como el aceite.

- En los aljibes de uso ganadero, especialmente después que entrara en ellos agua procedente de tormentas con granizo, ya que se pensaba que esta agua podía producir abortos.

- Como repelente de serpientes, poniendo unas gotas de miera en los marcos de puertas y ventanas.

- Para las muelas cariadas se ponían unas gotas de miera en la muela, mojando un algodón. Normalmente esto producía la pérdida de la pieza dental. Incluso algunos pastores nos han referido que se caían también las muelas de al lado. 


\subsection{La miera en fuentes documentales}

Dioscórides recoge en su tratado del siglo I dC el uso de un destilado de enebro que se recoge gota a gota y que denomina cedria (del nombre griego del enebro, cedro). Dice que es excelente la gruesa y transparente, de olor grave. Entre otras cosas, dice que corrompe los cuerpos vivos y conserva los muertos, clarifica la vista, mata los gusanos, metido en el horado del diente, lo quiebra y quita el dolor, con su untura mueren los piojos y las liendres, aplicado en unción es útil a los leprosos, mata las lombrices y los gusanos que parecen pepitas de calabaza, arranca la criatura del vientre. Se hace de la cedria un óleo, que se usa particularmente para la sarna de perros, bueyes y otros animales cuadrúpedos, mata las garrapatas y cura las llagas que se les hace al trasquilarlos. Añade en sus anotaciones Andrés de Laguna a este texto, que en Castilla no se halla la cedria legítima, que tiene gran semejanza con el aceite de enebro conocido como miera (Laguna, 1566).

Sin duda, cedria y miera coinciden en los usos, aunque la descripción que hace Dioscórides de la cedria como un destilado transparente no se corresponde con el color oscuro de la miera.

En la revisión del Dioscórides de Font Quer, este añade que la miera se emplea para curar llagas y úlceras, extendiendo sobre ellas una capita de miera. Cita también el uso veterinario que se hace de ella para la roña de los ganados y otras dolencias cutáneas (Font Quer, 1995).

En el año 1500, la Carta de los Reyes Católicos al Concejo de la Villa de La Roda regulando el almotacenazgo (un impuesto), fija el pago al almotacén de la venta de miera en dos maravedíes: Otrosy que qualquier forastero que vendiere en esa villa miel o miera dando medidas o peso para ello de al almotacan dos maravedis (Gil García, 1987).

En las ordenanzas municipales de Villarrobledo de 1591, transcritas a partir de otras de Alcaraz de 1587, aparecen las mereras en el punto 26: Yten, ordenaron que ninguno sea osado de hacer merera ni seruirse, ni aprovecharse de las fechas, ni pueda auer en los dichos dos annos mas de una, por ser uastantes para los ganados que ai en esta ciudad e su tierra de las eximidas; y el que la tubiere sea veçino desta ciudad, e que de ordinario tenga estanco de miera, e que las mereras fechas se derriben, y el que de nue- 
vo, en el dicho tiempo, hiçiere miera, incurra en pena de seis mil marauedis (Carrilero, 1992).

A comienzos del siglo XVI, en las mercancías que tenían obligación de pago al almotacén de Albacete, se fija a los barranos (forasteros) 1 maravedí por cada arroba de miera como pago del impuesto de almotacenía. En 1573 se fija como derecho de almotacenía en Albacete un tarrillo por carga de miera (Carrilero, 1997).

Miguel de Cervantes recoge también la miera en sus obras, citando en Rinconete y Cortadillo los untos de miera (Morales, 2005).

En el Arancel de Villarrobledo de 1627 aparece la miera, de la que han de pagarse sesenta maravedíes y un real por cada alumbre (Sepúlveda Losa, 2000).

En las actas capitulares de Alcaraz de 1583 y 1619 aparece la miera (Figuras 8 y 9). En el primer documento se señala la obligación de derribar todas las mereras menos dos, la del Charcón de Bartolomé Martínez y la del Cabalgador, de Alonso López. En el segundo documento se habla del abasto de la miera al que está obligado un tal Juan Saquero, para que haga un horno de miera en un lugar donde no haga daño a los montes de esa ciudad. 


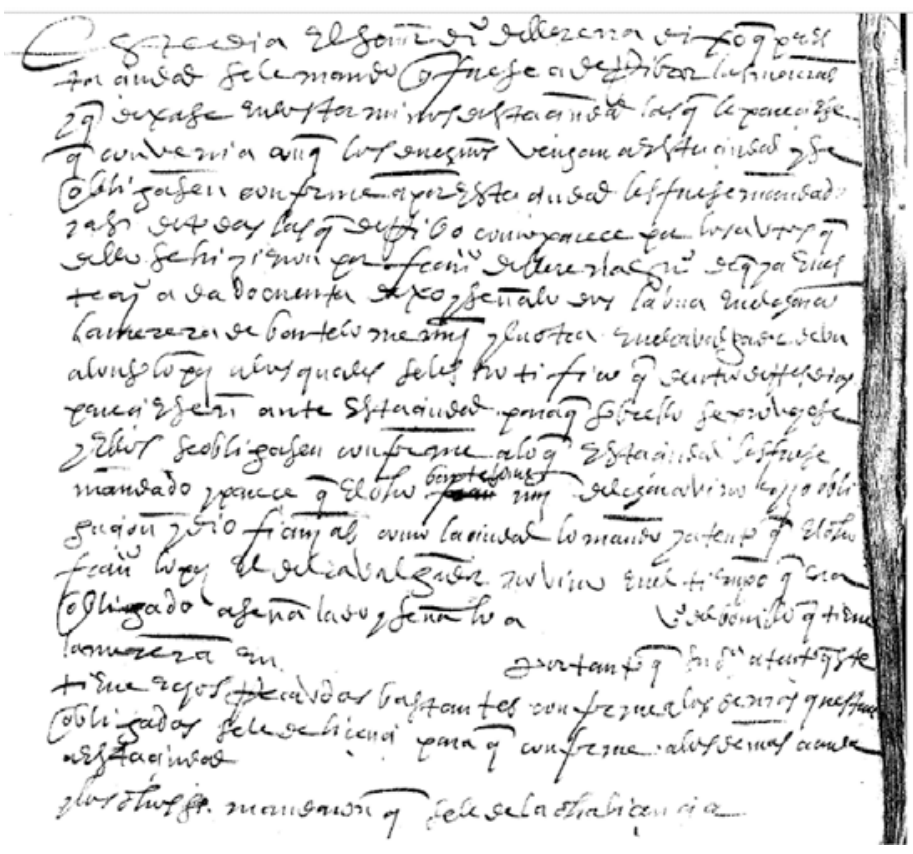

Este día el sr Diego de Llerena dixo que por esta ciudad se le mandó que fuese a derribar las mereras y que dexase en los términos desta ciudad las que pareciese que convenía aunque los dueños vengan a esta ciudad y se obligasen conforme a [lo que] por esta ciudad les fuese mandado y así se hizieron por Francisco de Llerena, escribano de que ya en este ayuntamiento ha dado cuenta, dixo y señaló dos: la una en el Charcón, la merera de Bartelomé Martínez y la otra en el Cabalgador de un Alonso López, a los cuales se les notificó que dentro de tres días pareciesen ante esta ciudad para que sobrello se proveyese y ellos se obligasen conforme a lo que esta ciudad les fuese mandado y parece que el dicho Bartelomé Martínez del Charcón, vino e hizo q obligación y dio fianzas como la ciudad lo mandó y atento que el dicho Francisco López, el del Cabalgador, no vino en el tiempo a que era obligado ha señalado y señaló a [vacio en el original] vecino del Bonillo que tiene la merera en [ ] ] por tanto que su señoría atento que éste tiene hechos recaudaos bastantes conforme a los demás que están obligados, se le dé licencia para que, conforme a los demás, acuda a esta ciudad [ ] y los dichos señores mandaron que se le dé la licencia

Figura 8. Sobre las mereras. IEA actas capitulares de Alcaraz Leg-602, exp-1, pág. 87, sesión del 22 de mayo de 1583 
Los protocolos notariales de Alcaraz hacen también referencia a la producción de miera: en 1646 se recogen dos posturas en carboneras oficiales de hacer miera y en actas capitulares del Ayuntamiento de Alcaraz, de 1654 , se nombra a un comisario para comprobar la veracidad de una noticia relativa a unos labradores que asisten en la Fuente del Pino, están haciendo miera y entran por leña para ellos al término de esta ciudad.

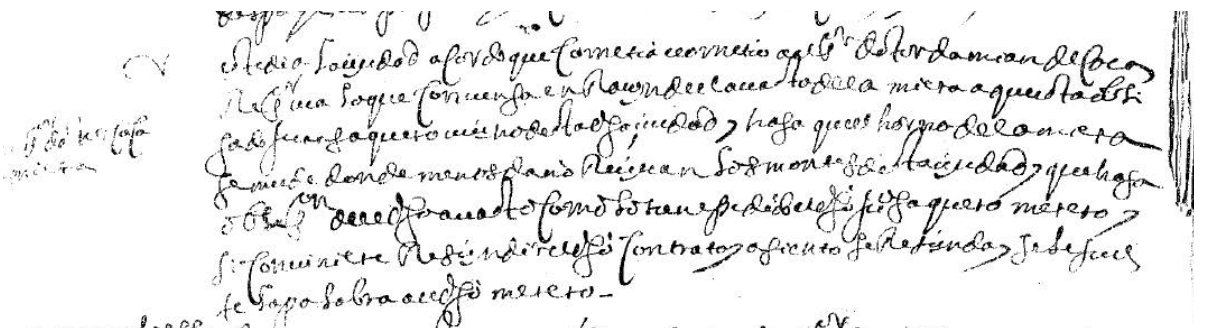

Este día la ciudad acordó que cometía e cometió (sic) a el sr. Doctor Damián de coca, regidor della lo que convenga en razón del abasto de la miera a que está obligado Juan Saquero, vecino desta dicha ciudad y haga que el horno de la miera se mude donde menos daño reciban los montes desta ciudad y que haga obligación de el dicho abasto, como lo tiene pedido el dicho Juan Saquero, merero, y si conviniere rescindir el dicho contrato y asiento se rescinda y se le ¿suelte? la palabra a el dicho merero.

Figura 9. Regulación de los hornos de miera en Alcaraz, en el siglo XVII. IEA actas capitulares de Alcaraz. Leg-603, exp-1, pág. 285, sesión del 16 marzo de 1619

En el Catastro de Ensenada (mediados del siglo XVIII) hay respuestas que incluyen la existencia de las miereras. En Alatoz se citan dos hornillos de miera, propios de Fernando y Quiteria Martínez, quienes hacen al año tres hornadas cada uno, sacando en ellas veinticuatro arrobas de miera, cuarenta y ocho entre los dos, siendo la utilidad particular doscientos ocho reales y la de ambos quinientos sesenta y seis. En las respuestas particulares aparece Fernando como labrador y fabricante de miera.

Alcaraz responde que en su término hay un horno de miera en el Rincón del Cabalgador y en un documento de 1748 se cita en este término el Cuarto de Mereras (Figura 10). Ossa tiene mereras en la Dehesa del Marañal en las que trabajan trece miereros (Eugenio de Mora, Die- 
go Albina, José Muñoz, Diego Cano, Juan Manuel Mota, Francisco Cano, Juan Francisco Martínez, Francisco Charco, Francisco Toledo, Francisco Muñoz, Alonso Moreno, Alonso Oliver y Antonio Muñoz) que ganaban al año 600 reales por la venta de este producto fuera de la Ossa. En ese documento de 1752 se dice que los miereros eran tratantes en hacer este aceite de enebro para la curativa de ganados menudos que sacan a vender a distintas partes. La abundancia de enebros y la existencia de estos hornos pudo ser una de las causas por las que la ciudad de Alcaraz fue reacia a ceder esta zona a los pueblos que se iban segregando de su vasto alfoz.

En Lezuza también existieron mereras en Lituero, Encinahermosa y en la Casa de la Merera. Pedro Jesús Gómez Sánchez, conocido en Lezuza como Pedro Merera, nació y pasó su infancia en la Casa de la Merera, recuerda que su padre le enseñaba los restos donde estaba el antiguo horno de miera, así como su uso. Con las reformas posteriores que se hicieron hace años en la aldea desaparecieron los pocos restos que quedaban de la vieja merera.

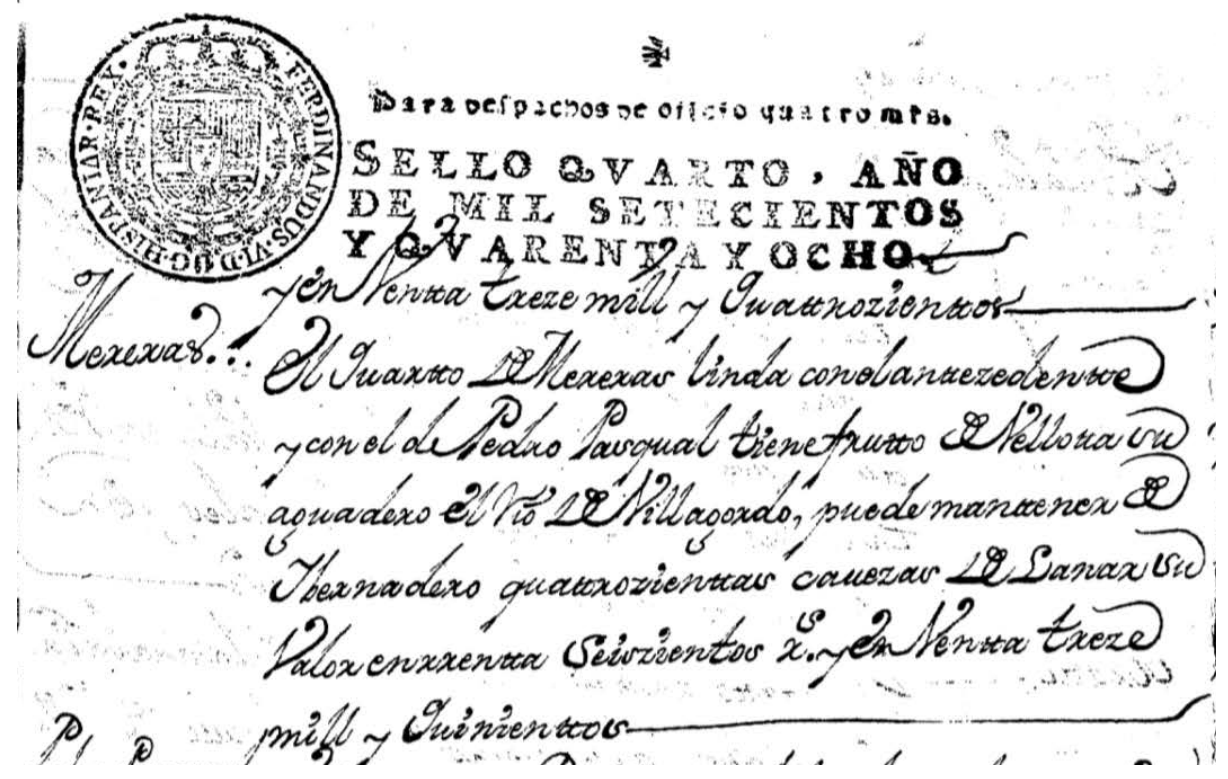

Figura 10. Cuarto de Mereras, Alcaraz 1748

En las respuestas de Lezuza al Catastro del Marqués de la Ensenada se dice sitio de Merera, pertenece a (bienes de) propios, un orno para sacar miera conducente a la curazion de ganados, que está junto al heredamiento de fuente pinilla. 
En El Bonillo también hubo mereras, según las respuestas dadas al Cardenal Lorenzana: y también abundancia de henebros, de cuyas raíces sacan de continuo mucha miera en dos miereras propias de esta villa (Fernández Chillerón, 2018). De estas miereras sólo hemos podido localizar una de ellas (Figura 13), la mayoría debieron perderse, ya que el mismo autor, al mencionar los productos que se venden en la feria de El Bonillo nos dice que se vende miera de Ossa de Montiel.

Francisco Martínez Villaescusa, médico titular de Tarazona de la Mancha, publica en 1777 un remedio eficaz para el temido carbunco. Este remedio consistía en un ungüento elaborado con lejía fuerte puesta a hervir hasta que quede con la consistencia de la miel recién sacada de un panal. Luego se le añade una tercera parte de miera, otra de jabón blando y otra de miel, se bate y se le añaden polvos de cal viva hasta que quede como un linimento espeso (Sánchez García, 2012).

En las Relaciones geográfico-históricas de Tomás López (17861789), en las respuestas de Ossa de Montiel se recoge: Enfrente de la Casa de la Salcedilla.... hay un orno para fabricar el Aceite de Enebro llamado Miera y se nomina el de Agibes. Entre la Caseria de Hortigosa, y Camino de Villa Robledo mirando à el Norte hay otro Orno de Miera llamado el Marañal. En cuanto a Alatoz, se recoge en la respuesta correspondiente a esta localidad: Ay muchos Ornos para sacar el Azeite de Enebro, ò Miera por otro termino que es la mas especial que se saca en estos Paises (Rodríguez de la Torre y Cano Valero, 1987).

A finales del s. XVIII, en sus anotaciones a las instrucciones para pastores y ganaderos de Daubenton, obra que tradujo y adaptó a las circunstancias españolas, Francisco González, maestro de la Real Escuela de Veterinaria de Madrid, indica que los pastores españoles usan mucho el aceite de enebro conocido como miera y lo llevan en el hato en liaras o en cuernos, usándolo para la roña y la sarna, aunque perjudica a la lana. Consideran la miera preventiva de muchas enfermedades, administrándola en el agua. Cuando tienen preparado y lleno el dornajo echan algunas gotas de este aceite con una pluma y se mezcla. Dicen que es un método extendido y valorado y de ahí el dicho: si los mayorales quieren gozar una buena paridera, denles sal y miera. Indica también que sirve para los gusanos (Daubenton, 1798). 
Ya en el siglo XIX encontramos varias referencias documentales a la miera en Albacete. Miñano (1828-1830) en la información referida a La Toz, señala en esta localidad la existencia de hornos de hacer miera (Rodríguez de la Torre, 1985). En el Boletín Oficial de la provincia de Albacete encontramos varias referencias a la miera; el 7 de marzo de 1860, se dice que el vecino de Higueruela, Francisco Oliver, había encontrado el 28 de febrero en un sitio llamado Cueva Negra una burra rucia, muerta, cargada de miera. En varias ediciones, en la década de 1870 aparece un anuncio en la sección no oficial en el que Pedro Lozano, pone en conocimiento de los ganaderos de la provincia, que ha establecido una fábrica de miera en Lezuza, en el caserío de Cina-hermosa y que venderá la miera al precio fijo de cuarenta reales la arroba (IEA, 2020).

\subsection{Mereras en Albacete. Localización}

La gran mayoría de las mereras ubicadas en la provincia han desaparecido. Se conservan algunas en buen estado en torno a la zona del Cabalgador (Ossa de Montiel), de otras se adivina su posición por los restos del horno y de otras no queda nada (tabla 1). Su presencia está bien reflejada en la toponimia (Figura 11).

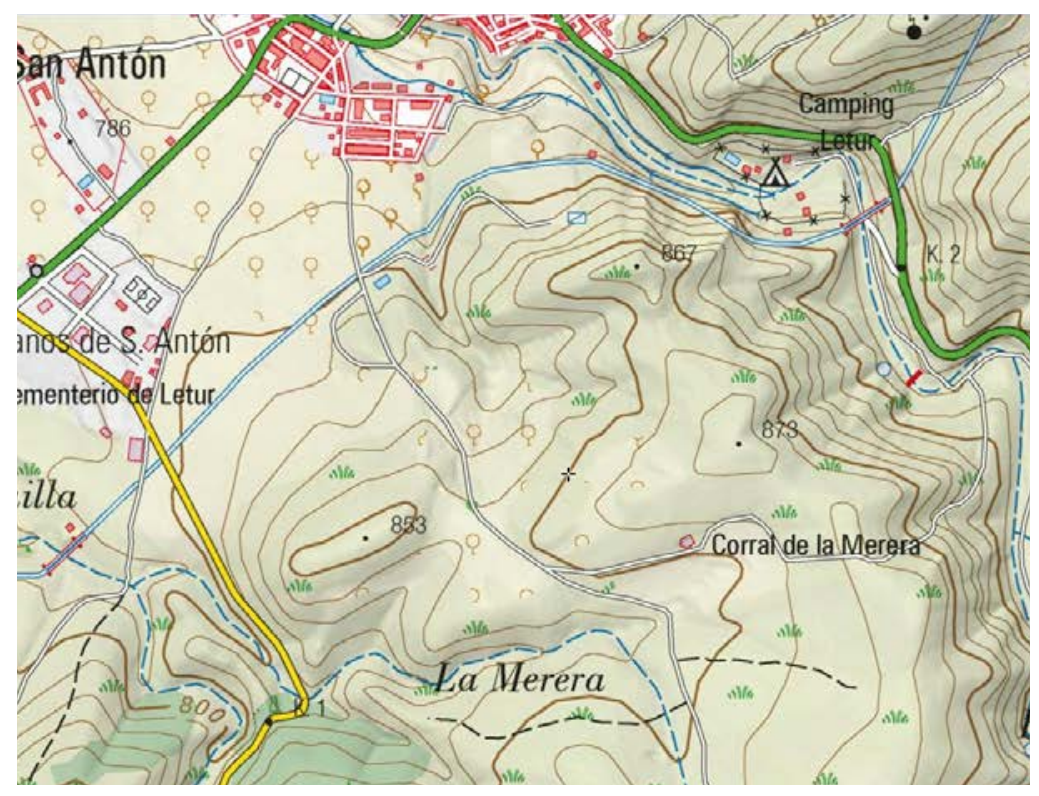

Figura 11.

El rastro de las mereras en la Toponimia. Paraje de la Merera y Corral de la Merera (Letur). Al norte del mapa, el casco urbano de esta población (mapa: iberpix). 


\begin{tabular}{|c|c|c|c|}
\hline $\begin{array}{c}\text { Término } \\
\text { Municipal }\end{array}$ & $\begin{array}{c}\text { Denominación } \\
\text { del paraje }\end{array}$ & Observaciones & Estado \\
\hline Alatoz & $\begin{array}{l}\text { Cerro de las } \\
\text { Mereras }\end{array}$ & $\begin{array}{l}\text { Aunque el paraje } \\
\text { es conocido con } \\
\text { este nombre } \\
\text { en la localidad, } \\
\text { en el mapa } \\
\text { topográfico } \\
\text { aparece como } \\
\text { Cerro de las } \\
\text { Moreras }\end{array}$ & $\begin{array}{l}\text { Se conservan } \\
\text { algunos restos } \\
\text { (Figura 6) }\end{array}$ \\
\hline Alcaraz & $\begin{array}{l}\text { Cuarto de } \\
\text { Mereras }\end{array}$ & $\begin{array}{l}\text { En protocolos } \\
\text { notariales, se } \\
\text { cita cercana al } \\
\text { aguadero de } \\
\text { Villalgordo } \\
\end{array}$ & Sin localizar \\
\hline Alcaraz & $\begin{array}{l}\text { Vallejo de } \\
\text { la Merera. } \\
\text { Próximo a Las } \\
\text { Alamedas } \\
\text { (El Jardín) }\end{array}$ & $\begin{array}{l}\text { Podría } \\
\text { relacionarse } \\
\text { con el Cuarto } \\
\text { de Mereras. } \\
\text { Aparece } \\
\text { en el Mapa } \\
\text { Topográfico } \\
\text { Nacional }\end{array}$ & $\begin{array}{l}\text { Sin localizar la } \\
\text { merera con la que } \\
\text { se relaciona }\end{array}$ \\
\hline Ayna & La mierera & \begin{tabular}{|l} 
Paraje cercano \\
a la aldea de La \\
Sarguilla \\
\end{tabular} & $\begin{array}{l}\text { En la toponimia, } \\
\text { sin localizar }\end{array}$ \\
\hline $\begin{array}{l}\text { Casas de } \\
\text { Lázaro }\end{array}$ & La Merera & $\begin{array}{l}\text { Cerrillo muy } \\
\text { cercano al } \\
\text { pueblo, a unos } \\
500 \mathrm{~m} .\end{array}$ & $\begin{array}{l}\text { En la toponimia, } \\
\text { sin localizar }\end{array}$ \\
\hline El Bonillo & Mereras & $\begin{array}{l}\text { En las } \\
\text { Descripciones } \\
\text { del Cardenal } \\
\text { Lorenzana }\end{array}$ & $\begin{array}{l}\text { Se conserva } \\
\text { una merera } \\
\text { semiderruida en } \\
\text { la Rambla (Figura } \\
\text { 13) }\end{array}$ \\
\hline
\end{tabular}




\begin{tabular}{|c|c|c|c|}
\hline Letur & $\begin{array}{l}\text { La Merera y } \\
\text { Corral de la } \\
\text { Merera }\end{array}$ & $\begin{array}{l}\text { Paraje cercano al } \\
\text { pueblo, apenas a } \\
\text { un } \mathrm{km} \text {. Al sur de } \\
\text { Letur }\end{array}$ & $\begin{array}{l}\text { En la toponimia, } \\
\text { sin localizar }\end{array}$ \\
\hline Lezuza & $\begin{array}{l}\text { Casa de la } \\
\text { Merera }\end{array}$ & $\begin{array}{l}\text { Se cita en el } \\
\text { catastro del } \\
\text { Marqués de } \\
\text { la Ensenada. } \\
\text { Se conserva el } \\
\text { topónimo }\end{array}$ & $\begin{array}{l}\text { Totalmente } \\
\text { desaparecida }\end{array}$ \\
\hline Munera & $\begin{array}{l}\text { Cerro de la } \\
\text { Merera }\end{array}$ & En la toponimia & $\begin{array}{l}\text { En el lugar de la } \\
\text { posible ubicación } \\
\text { existe un majano } \\
\text { de piedras }\end{array}$ \\
\hline $\begin{array}{l}\text { Ossa de } \\
\text { Montiel }\end{array}$ & $\begin{array}{l}\text { Merera del } \\
\text { Charco (o del } \\
\text { Charcón), } \\
\text { cercana al } \\
\text { Marañal }\end{array}$ & $\begin{array}{l}\text { Las mereras de } \\
\text { la Dehesa del } \\
\text { Marañal en Ossa } \\
\text { se citan en libros } \\
\text { capitulares de } \\
\text { Alcaraz (1583) y } \\
\text { en el catastro del } \\
\text { marqués de la } \\
\text { Ensenada }\end{array}$ & $\begin{array}{l}\text { En buen estado de } \\
\text { conservación (no } \\
\text { visitables) }\end{array}$ \\
\hline $\begin{array}{l}\text { Ossa de } \\
\text { Montiel }\end{array}$ & $\begin{array}{l}\text { Merera del } \\
\text { Rincón }\end{array}$ & $\begin{array}{l}\text { Se cita en libros } \\
\text { capitulares de } \\
\text { Alcaraz (1583) y } \\
\text { en el Catastro de } \\
\text { Ensenada }\end{array}$ & $\begin{array}{l}\text { Bien conservada, } \\
\text { se halla en una } \\
\text { vivienda particular } \\
\text { (no visitable) }\end{array}$ \\
\hline Villarrobledo & $\begin{array}{l}\text { La mierera } \\
\text { y Casa de la } \\
\text { Mierera }\end{array}$ & $\begin{array}{l}\text { Paraje bastante } \\
\text { próximo al } \\
\text { Rincón, unos } \\
7 \text { km. En línea } \\
\text { recta }\end{array}$ & $\begin{array}{l}\text { Restos de la } \\
\text { ubicación (Figura } \\
14 \text { ) }\end{array}$ \\
\hline
\end{tabular}

Tabla 1. Mereras y topónimos relacionados en fuentes históricas, topográficas y orales en Albacete 


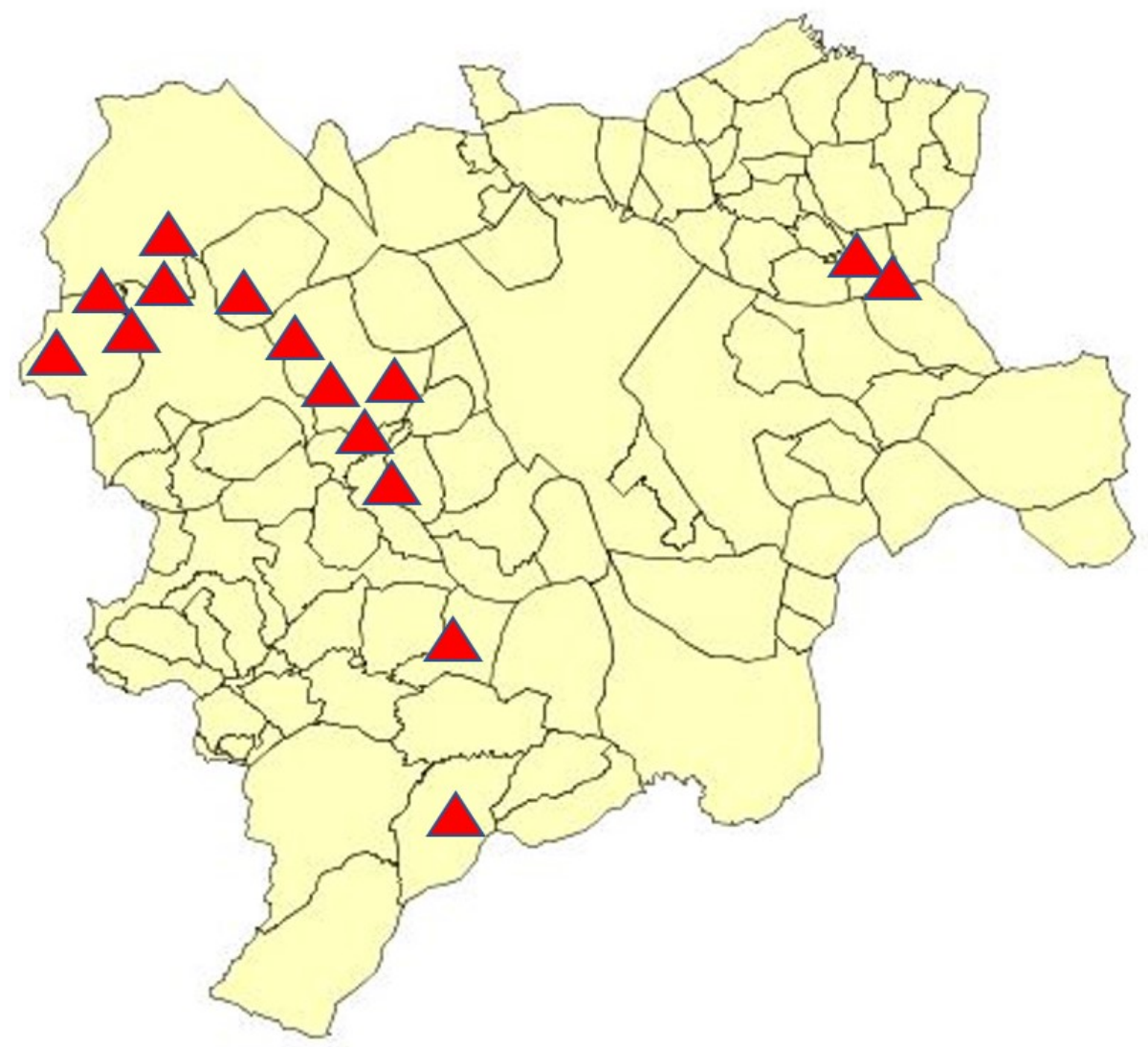

Figura 12. Mapa, mereras localizadas en la provincia de Albacete (elaboración propia).

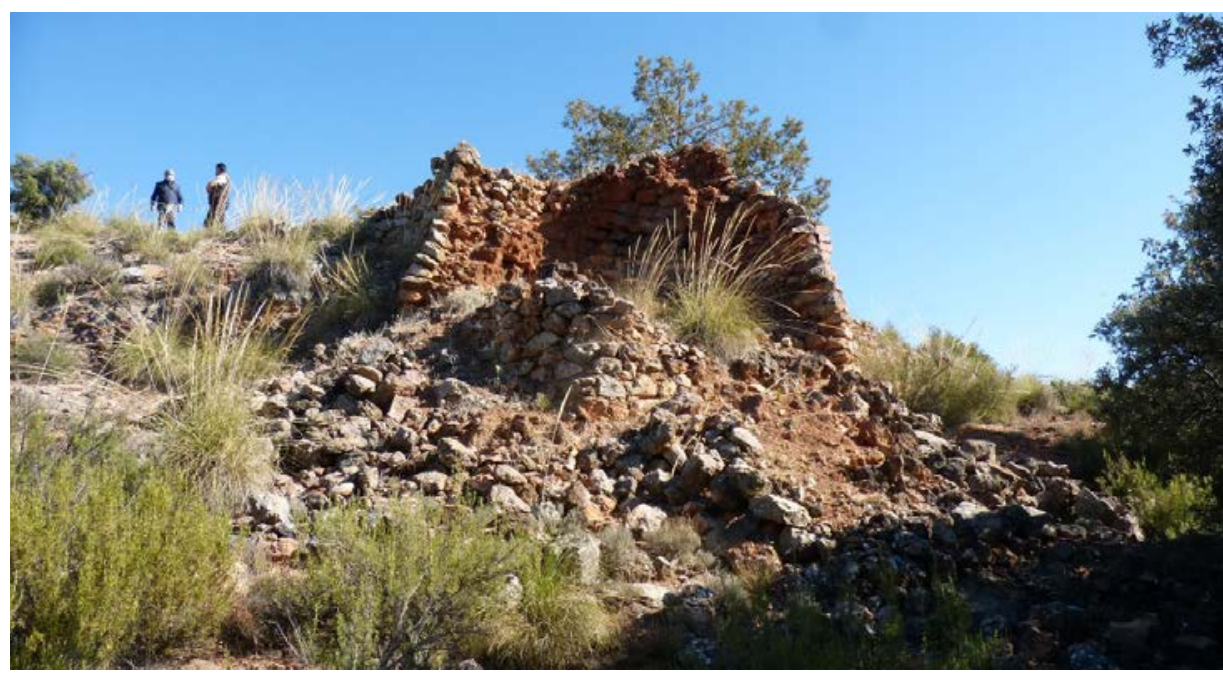

Figura 13. Merera de la antigua dehesa concejil de El Bonillo. (Foto: José Fajardo). 


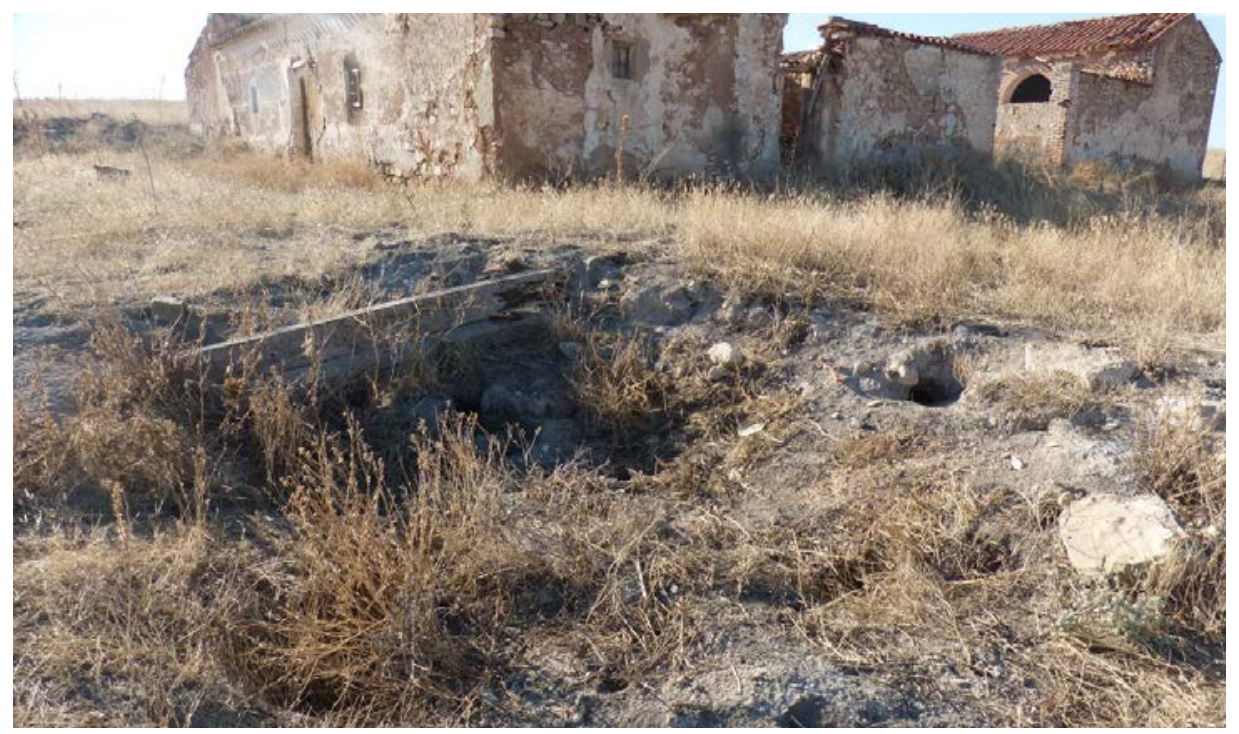

Figura 14. Posible ubicación de las antiguas mereras de la Casa de la Mierera (Villarrobledo). En primer término, se aprecian los restos de una base de mampostería y tierra carbonizada (Foto: José Fajardo).

\section{DISCUSIÓN Y CONCLUSIONES}

El enebro es una planta esencial en el paisaje vegetal albacetense, no sólo por su presencia en el medio natural, sino también por la importancia que ha tenido su aprovechamiento en la producción de miera. Éste es un remedio antiquísimo empleado en la veterinaria popular que entró en desuso hace décadas con la generalización de productos comerciales como el conocido zotal.

La evidencia documental y las entrevistas a pastores y ganaderos señalan la importancia que tuvo la miera en Albacete durante siglos, tanto en la ganadería como en la economía local. Especialmente, en dos localidades que destacan en la provincia por la elaboración y venta de miera: Alatoz y Ossa de Montiel.

Las mereras que aún se conservan deben mantenerse como bien de interés cultural, testimonio de una actividad ancestral. Se debe apoyar su catalogación y conservación. En este sentido, como ejemplo, algunas de las mereras tradicionales conservadas en Riba-Roja d'Ebre (Tarragona) están catalogadas como Bien Cultural de Interés Local y esta localidad celebra cada año su fiesta del aceite de enebro (Festa de l'Oli de Ginebre) 
como una reivindicación de esta seña de identidad del municipio (Ajuntament de Riba-roja d'Ebre en www.riba-roja.cat).

Esta revisión abre nuevos interrogantes sobre la historia de este recurso natural, entre ellos, las posibles vinculaciones del uso de la miera y el establecimiento de mereras con la expansión ganadera que siguió a la reconquista y conocer si también se usó la miera en la España andalusí o apareció ligada a la ganadería castellana.

\section{AGRADECIMIENTOS}

Miguel Cambronero, de Robledo, nos ha hecho llegar varias de las referencias documentales citadas en este artículo donde aparecen miera y mereras.

Agradecemos también a Gabriel y Kica Muñoz, de Peñarrubia del Alto Guadiana (Ossa de Montiel) sus explicaciones sobre el proceso de destilación de la miera y habernos mostrado amablemente mereras y enebrales.

En Alatoz, el pueblo de los de la miera, Pepe Gómez, nos ha acompañado a rastrear las antiguas mereras, entre cinglas y vallejos, del Cerro de las Mereras.

Pedro Moya, de El Bonillo, Juan Flores, de Munera y Juan José Fernández, de Ossa de Montiel, nos enseñaron la ubicación de algunas de las antiguas mereras que rodean el Cabalgador.

Han sido muchos los pastores y ganaderos, especialmente los de mayor edad, los que nos han hablado de la miera y de sus usos. A todos ellos les estamos profundamente agradecidos por compartir con nosotros sus vivencias y sus testimonios. 


\section{BIBLIOGRAFÍA}

Abdellah, F., Laid, B. Hammoudi, S. M. and Benaraba, R. (2018). In vitro evaluation of the Antimicrobial and Antioxidant activities of Juniperus oxycedrus essential oil (Cade oil). International Journal of Innovation Engineering and Science Research 2 (6): 66-76

Ajuntament de Riba-roja d'Ebre (2020). En www.riba-roja.cat (Consultado en línea, 13 noviembre 2020).

Al-Snafi, A. E. (2018). Pharmacological and therapeutic effects of Juniperus oxycedrus. A review. IndoAmerican Journal of Pharmaceutical Sciences 2018, 05 (04), 2198-2205.

Benlloch, V. y Martín, A. (2015). Árboles singulares de la provincia de Albacete. Ed. Instituto de Estudios Albacetenses "Don Juan Manuel". Diputación de Albacete. Albacete. 432 pp.

Blanco, E., Gutiérrez, M. J. y Pintor, E. (2018). Etnofarmacología de las comarcas de Alto Tajo y Señorío de Molina (Guadalajara): plantas medicinales de uso tradicional, En Cuadernos de etnología de Guadalajara 50: 237-266.

Cabezón, C. (1997). Diccionario de Plantas Medicinales. Según la medicina tradicional marroquí. Ed. Noesis. Madrid. 432 pp.

Carrilero, R. (1992). Ordenanzas municipales de Villarrobledo (14721623). Ed. Instituto de Estudios Albacetenses. Diputación de Albacete. Albacete. $201 \mathrm{pp}$.

Carrilero, R. 1997. (1997). Ordenanzas de Albacete del siglo XVI. Edición crítica y estudio documental. Ed. Instituto de Estudios Albacetenses. Diputación de Albacete. Albacete. 365 pp.

Charco, J., Fernández, F., García, R., Mateo, G. y Valdés, A. (2008). Árboles y arbustos autóctonos de Castilla-La Mancha. Ed. CIAMED. Ciudad Real. 504 pp.

Cruz Herrera, M. P. (2004). Diccionario de gentilicios y pseudogentilicios de la provincia de Albacete. Zahora n ${ }^{\circ} 42$. Ed. Diputación de Albacete. Albacete. 170 pp.

Daubenton, C. (1798). Instrucción para pastores y ganaderos. Ed. Facsímil. Ministerio de Agricultura y Pesca, Alimentación y Medio Ambiente. Madrid. 336 pp. 
DRAE (2020). Miera. En dle.rae.es/miera (Consulta en línea, 3 de octubre de 2020).

Ezzaki, I. F., Mtioui, N., Medkouri, G., Zamed, M. and Ramdani, M. B. (2020). Acute Renal Failure Following Popsioning by Juniper Tar (Cade Oil). Journal of Clinical Toxicology 10 (4) 1-4.

Fajardo, J., Verde, A., Rivera, D. y Obón, C. (2000). Las plantas en la cultura popular de la provincia de Albacete. Ed, Instituto de Estudios Albacetenses “Don Juan Manuel”. Diputación de Albacete. Albacete. 264 pp.

Fernández Chillerón, R. (2018). La feria de El Bonillo en el aniversario de su concesión. Ed. Ayuntamiento de El Bonillo, Concejalía de Cultura. El Bonillo (Albacete). 336 pp.

Font Quer, P. (1995). Plantas Medicinales. El Dioscórides renovado. Ed. Labor. Barcelona. 1033 pp.

Gil García, P. (1987). Portazgo y Almotacenazgo en La Roda en Albacete a fines de la Edad Media. En Pretel Marín A. Congreso de Historia del Señorío de Villena. Ed. Instituto de Estudios Albacetenses. Diputación de Albacete. Albacete. 433 pp.

IEA (2020). En http://iealbacetenses.dipualba.es/index. vm?view=main\&lang=es (Consultado en línea, 9 de enero de 2021). Jordán Montes, J. F. (2018). Sierra, llanura y río: Oficios en la serranía de los ríos Segura y Mundo y otras vivencias en el bosque y en la montaña. Ed. Instituto de Estudios Albacetenses “Don Juan Manuel”. Diputación de Albacete. Albacete. 1215 pp.

Laguna, A. (1566). Pedacio Dioscórides Anazarbeo, acerca de la Materia Médica Medicinal y de los Venenos Mortíferos. Ed. Facsímil. Biblioteca de Clásicos de la Medicina y de la Farmacia Española. Fundación de Ciencias de la Salud. Madrid. 616 pp.

Koruk, S. T., Ozyilkan, E., Kaya, P. and Colak, D. (2005). Juniper Tar Poisoning. Clinical Toxicology 43 (1): 47-9

Monesma, E. (2017). El aceite de enebro. En www.pyrenepv.com/aceiteenebro (Consultado en línea, 13 noviembre 2020).

Morales, R. (2005). Flora literaria del Quijote: Alusiones al mundo vegetal en las obras completas de Cervantes. Ed. Instituto de Estudios Albacetenses “Don Juan Manuel”. Diputación de Albacete. Albacete. 198 pp. 
Rivera, D., Matilla, G., Obón, C. and Alcaraz, F. (2011). Plants and Humans in the Near East and the Caucasus (vol. 1). Ed. Universidad de Murcia. Murcia. 341 pp.

Rodríguez de la Torre, F. (1985). Albacete en textos anteriores a la creación de la provincia. Ed. Instituto de Estudios Albacetenses. Diputación de Albacete. Albacete. 324 pp.

Rodríguez de la Torre, F. y Cano Valero, J. (1987). Relaciones geográficohistóricas de Albacete (1786-1789) de Tomás López. Ed. Instituto de Estudios Albacetenses. Diputación de Albacete. Albacete. 364 pp.

Sánchez, M. D., García, J. A., Gómez, A. y Zon, S. (1994). Plantas útiles de la comarca de La Manchuela (Albacete). Ed. CEDER La Manchuela, Casas Ibáñez (Albacete). 190 pp.

Sánchez García, M. A. (2012). Sociedad, medicina e ilustración en el mundo rural albacetense: Francisco Martínez Villaescusa (1740-1793). Ed. Instituto de Estudios Albacetenses “Don Juan Manuel”. Diputación de Albacete. Albacete. 269 pp.

Sepúlveda Losa, R. M. (2000). Arancel de Villarrobledo de 1627. Ed. Instituto de Estudios Albacetenses “Don Juan Manuel”. Diputación de Albacete. Albacete. 252 pp.

Verde, A., Rivera, D. y Obón, C. (1998a). Etnobotánica en las sierras de Segura y Alcaraz: las plantas y el hombre. Ed. Instituto de Estudios Albacetenses, Diputación de Albacete. Albacete. 351 pp.

Verde, A., Rivera, D., Obón, C. y Fajardo, J. (1998b). Medicina Popular en la provincia de Albacete. Las plantas medicinales: usos, creencias y leyendas. Zahora 28. Diputación de Albacete. Albacete. 119 pp.

Verde, A., Rivera, D., Fajardo, J., Obón, C. y Cebrián, F. (2008). Guía de las plantas medicinales de Castilla-La Mancha. Ed. Altabán. Albacete. $528 \mathrm{pp}$.

Vilar, L., Caudullo, G., de Rigo, D., (2016). Juniperus oxycedrus in Europe: distribution, habitat, usage and threats. In: San-Miguel-Ayanz, J., de Rigo, D., Caudullo, G., Houston Durrant, T., Mauri, A. (Eds.), European Atlas of Forest Tree Species. Publ. Off. EU, Luxembourg. 197 pp. VV.AA. (2005). A Guide to Medicinal Plants in North Africa. Ed. IUCN, Málaga. 256 pp. 